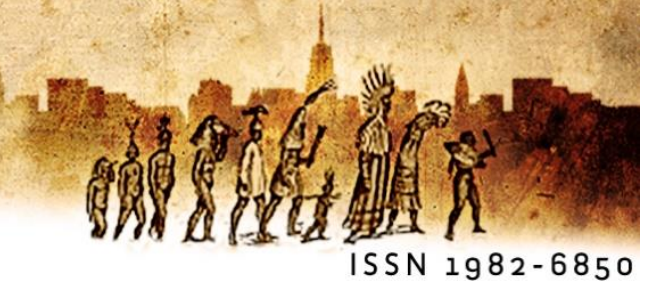

\title{
GEORGES BATAILLE: \\ O PRAZER DO PEDAÇO E DA DISSOLUÇÃO
}

\author{
GEORGES BATAILLE: \\ LE PLAISIR DE PIÈCE ET LA DISSOLUTION
}

Fábio Andrade (UFPE)

\begin{abstract}
Resumo:
A obra inclassificável de Georges Bataille suscita uma série de reflexões profundamente atuais, que vão desde as potências irrefreáveis do corpo até a compreensão do caráter transgressor do olhar. Olhar alucinado, encontrando paralelo inclusive no caráter alucinado do pensamento e do texto de Bataille. O que prova, por sua vez, a importância nuclear que as relações entre o olhar e o visível ocupam em sua escritura sempre destinada à transgredir certos limites e fronteiras. Assim, entender as repercussões desse olhar que encena o voyeurismo como dissolução do eu traduz aquilo que o próprio Bataille denominou de erotismo sagrado, enquanto experiência fundamental da potência erótica e desafio à tradição racionalista da filosofia ocidental.

Palavras-chave: Georges Bataille; Prazer; Olhar; Dissolução.

\section{Resumé:}

Le travail sans prétention de Georges Bataille soulève une série de réflexions profondément actuelles, allant des pouvoirs débridés du corps à la compréhension du caractère transgressif du regard. Regard hallucinant, parallèle même dans le caractère halluciné de la pensée et du texte de Bataille. Cela prouve, à son tour, l'importance nucléaire que les relations entre le regard et le visible occupent dans son écriture, toujours destinées à transgresser certaines limites et frontières. Comprendre les répercussions de ce regard qui traduit le voyeurisme en tant que dissolution de soi traduit ce que Bataille lui-même appelle l'érotisme sacré comme une expérience fondamentale du pouvoir érotique et un défi à la tradition rationaliste de la philosophie occidentale.

Mots-clés: Georges Bataille; Plaisir; Régard; Dissolution.
\end{abstract}




\section{Introdução}

Georges Bataille ocupa um lugar peculiar no universo do pensamento e da literatura de língua francesa. Transitando entre a literatura, a antropologia, a filosofia, a iconologia, a teoria da arte e a teologia, a trajetória de Bataille pode ser interpretada como o exercício de uma espécie de promiscuidade epistemológica.

Entre todos esses saberes, destaca-se, porém, um objeto de interesse constante e que pode ser encarado, não sem variadas implicações, como o elo capaz de coligá-los: a potência erótica. O desejo, as forças de prazer e dor do corpo pressionaram de maneira radical o pensamento e a linguagem de Bataille até os limites, tanto do pensamento como da linguagem. Até ao ponto de fazer a experiência - noção fundamental para compreender a postura do escritor e do pensador Bataille diante dos fenômenos - revelar-se como uma seara inalcançável, esquiva às reduções do pensamento e ao caráter representativo da linguagem.

São esses limites, sempre questionados, sempre violentados que permitem compreender a tensão, por exemplo, entre imagem e texto na obra de Bataille. E a principal motivação para a elaboração de sua iconografia "dilacerante e dilacerada", como a denomina Georges Didi-Huberman (2015). As imagens dessa iconografia, selecionadas desde muito cedo, desde sua atuação, por exemplo, como editor da revista Documents, não representam meros apoios ilustrativos ou explicativos do que se desenvolve na dimensão propriamente textual. Ao contrário, a função das imagens é tensionar, questionar e alucinar o texto - no sentido etimológico, inclusive, da palavra: fazer o texto se perder, vagar, perturbar-se. ${ }^{1}$ Um dos princípios fundamentais da obra de Bataille, seja no âmbito da criação literária, seja no âmbito do pensamento, é o da perturbação. O procedimento de perturbação acompanhou o desdobramento de sua obra até o final da vida, basta pensar no papel fundamental das imagens que atravessam um livro como O erotismo (2013). Evidente que o caráter perturbador de sua obra não se encontra apenas na fricção da imagem contra

\footnotetext{
${ }^{1}$ Essa noção de Texto alucinado refletiria, por sua vez, um pensamento alucinado. Insisto na etimologia do termo, marcada pelo sentido de vagar, errar, perder-se. No âmbito textual propriamente dito isso pode ser verificado no caráter incompleto, inconcluso e aberto da escritura de Bataille; nas mudanças tonais de seus texto, do ensaio para o tratado, no meio do tratado os aforismos, misturando confissão e especulação filosófica.
} 
o texto, mas também no gosto pela obscenidade. Obsceno ${ }^{2}$ seria o efeito que decorre da transgressão de um interdito: mostrar o que não deveria ser mostrado, ver o que não deveria ser visto. Assim, o sexo, os excrementos, a violência, a perversão aparecem todos como componentes desse efeito obsceno produzido por uma obra que elege a potência erótica e o corpo como seus principais modos de expressão.

A noção de perturbação começa na própria concepção de Bataille da experiência artística, concebida como capaz de englobar todos os aspectos não artísticos da existência não uma beleza que fizesse do feio belo; mas uma "beleza" que fosse bela e feia. Daí a crescente divergência entre Bataille e os surrealistas, pois há no discurso surrealista, segundo Fernando Scheibe, "um excesso de metáforas de pureza, como se essa convulsão do real que é a beleza pudesse se dar sem sangue, sem porra, sem merda" (2013, p.11). Enfim, sem os resíduos corporais; que exerceram na sua ficção um papel significativo.

Karl Erik Schöllhammer, em seu ensaio Além do visível (2011), no capítulo dedicado a Bataille, assinala a metamorfose perturbadora do olho ao longo de um romance como Histoire de l'oeil (História do Olho). O ápice desse verdadeiro romance de deformação é a cena em que a jovem personagem Simone introduz na vagina o olho de um padre que ela, 0 narrador e um terceiro personagem - Sir Edmond - acabaram de estrangular. O narrador, então, oscilando entre testemunha e partícipe dos caprichos bizarros e libidinosos de Simone, tem a impressão que o globo ocular do padre o observa de dentro da fissura peluda da personagem. Para Erik-Schölhammer,

Bataille relaciona a cegueira com a enucleação - o ato de retirar o olho da órbita - rompendo a relação privilegiada da visão, tradicionalmente compreendida como portadora do sentido da razão e do espírito, e reintroduzindo o órgão ocular no corpo de uma maneira que provoca ao mesmo tempo horror e êxtase orgiástico. (2016, p.73)

Assim, como bem vê o crítico, a questão do olhar, ou melhor, a questão do visível permeia todo o pensamento e a obra de Bataille, transformando-se num elemento perturbador tanto do pensamento quanto da linguagem. Pois a questão que Bataille nos coloca é: pode o olhar ser domado? O olhar que percorre com igual despudor, e um prazer

\footnotetext{
${ }^{2}$ Apesar da etimologia de "obsceno" ser de origem incerta, levo em consideração certa tradição que, sem poder ser completamente desmentida, via no termo a expressão do que está fora da cena. Outro significado, insistirão os latinistas atuais, para a origem etimológica do termo é a de "contra a sociedade".
} 
quase inconfessável, a mais plena beleza e o maior horror? E ainda mais insistentemente, nos pergunta Bataille: até onde suportamos olhar?

\section{A transgressão do olhar e o voyeur}

O lugar que os narradores de Bataille ocupam talvez seja um lugar paradigmático do discurso literário erótico. No caso específico da História do olho, sequer do nome do narrador o leitor é informado. Em relação à ação da narrativa, o narrador se coloca como um devoto, seguindo Simone na realização de seus desejos e jogos eróticos mais extravagantes e duplicando inclusive a paixão dela pela adolescente Marcela, uma espécie de duplo da própria Simone. Configura-se como um narrador testemunha ${ }^{3}$, assistindo e participando simultaneamente de cada nova aventura erótica. O fascínio que a personagem Marcela produz nele só encontra paralelo na sua devoção a Simone: "Naquele momento, não me passava pela cabeça qualquer idéia que não fosse a de me devotar, até o resto de meus dias, àquela aparição irreal" (BATAILLE, 2018, p.43).

É predominantemente como expectador que o narrador participa das duas seqüências que compõem o clímax da História do olho: a tourada, em que Simone goza ao assistir o toureiro ser morto pelo touro, o chifre penetrando o globo ocular e ela introduzindo os testículos de um touro na vagina; e a do assassinato do padre, após ele sucumbir aos encantos de Simone e ser, nas palavras do Sir Edmond, "martirizado, mas trepando" (2018, p.68); o ponto mais alto desse clímax transgressor de libertinagem e crime encontra-se nesse final, na profanação do padre e do ambiente religioso. É possivelmente a seqüência narrativa que mais sugere a configuração do ambíguo título da narrativa. Cena que culmina na já relatada extração do olho do padre para a vagina de Simone; e que vale transcrever para comentar melhor o jogo "ocular" da narrativa:

- Enfie-o no meu cu - gritou Simone.

\footnotetext{
3 Utilizo a nomenclatura do foco narrativo de Norman Freadman, pois a considero, diferente da nomenclatura estruturalista, mais acessível.
} 
Sir Edmond enfiou o olho na fenda e empurrou.

Por fim, Simone se afastou de mim, tirou o olho das mãos de Sir Edmond e o introduziu na boceta. Puxou-me nesse momento para junto dela, beijou o interior de minha boca com tanto ardor que tive um orgasmo; minha porra espirrou nos seus pentelhos.

Levantando-me, afastei as coxas de Simone: Ela jazia no chão, de lado; encontrei-me então diante daquilo que - imagino - eu sempre esperara: assim como a guilhotina espera a cabeça que vai decepar. Meus olhos pareciam estacados de tanto horror; vi, na vulva peluda de Simone, o olho azul-pálido de Marcela a me olhar, chorando lágrimas de urina. Rastros de porra no pelo fumegante conferiam a esse espetáculo um aspecto de dolorosa tristeza (BATAILLE, 2018, P.71).

A voz narrativa de Bataille nos convida a ocupar esse lugar, o lugar do voyeur. Nesse exercício de mixoscopia, a condição do narrador adquire significados que extrapolam o plano narrativo da História do olho, com repercussões enormes em toda a sua obra.

O lugar ambíguo e incerto do voyeur, um não-eu, configura-se não só como aquele que observa como também aquele que é observado. Ele observa o gesto último do ritual insólito encenado por Simone, ele olha o outro olho de Simone, o novo; e é observado por ele. É esse jogo que derrui a fixidez segura de quem olha o que não deveria ser olhado; pois olhar, já é também ser observado.

Esse voyeurismo é um lugar de dissolução do sujeito, que pode ser qualquer um ${ }^{4}-$ ele, eu, você, ninguém. Ou dizendo de outro modo: o voyeur é essencialmente o um qualquer. O discurso literário erótico é uma cumplicidade do olhar, que indica que todos nós nos colocamos nesse lugar de atração e negação que é o do voyeur, porque transgressivo (olhar o que não pode ser olhado). O desejo é uma realidade que nos toca a todos, mais ou menos explicitamente. O voyeurismo da narrativa erótica é a comunicação de um segredo e o reconhecimento de que ninguém foge aos apelos do corpo, mesmo - e talvez principalmente - que esses apelos circulem nos corredores subterrâneos de nossa imaginação. Ainda um pouco além: representa a potência despersonalizante do desejo sexual, da experiência orgástica que tem como uma de suas principais conseqüências a implosão do "eu".

\section{Erotismo sagrado, experiência erótica e dissolução do eu}

\footnotetext{
${ }^{4}$ Importante lembrar não só o fato de que o narrador não tem nome, como também o fato do romance ter sido publicado sob o pseudônimo de Lorde Auch.
} 
Essa reconfiguração do corpo, o olho deslocado da órbita e fixado na fissura do sexo de Simone, é uma das formas de transgressão que corre em paralelo com a transgressão do olhar. A aparência do corpo, em sua configuração clássica, onde cada coisa está no seu devido lugar, funcionando como uma máquina perfeita e harmônica, concebido sob proporções áureas e belas, é destruída por esse processo de deslocamento violento.

Essa outra visão, nascida de um jogo, de uma incerteza, de uma dúvida intransponível - quem olha quem? - sugere outro indício muito significativo. O olho retirado do topo do corpo, da cabeça, onde deveria estar como lanterna da razão e da verdade, recondicionado ao ambiente úmido e cavernoso do sexo de Simone, já prefigura a imagem do acéfalo - pois não é mais a partir da cabeça que se vê, mas a partir do corpo metaforicamente sem cabeça. Nesse sentido, a própria figura do acéfalo como desenhada por André Masson e que exercerá tanta sedução sobre Bataille, não deixa de ser uma figuração simbólica da vulva, em oposição ao corpo com cabeça do falo.

A deformação, destruição e reconfiguração do corpo, como bem vê Georges DidiHuberman em seu importante ensaio - A semelhança Informe (2015) - está em sintonia com o ataque potente de Bataille contra o racionalismo ocidental que tem como uma de suas premissas e bases fundamentais o "eu". Não só o caráter alucinatório, obsceno, aberto e inacabado do texto de Bataille investem na dissolução do eu pela potência erótica; igualmente toda a dissonante iconografia que ele compôs tem como um de seus principais objetivos transgredir as formas, que seria, por sua vez, nas palavras de Didi-Huberman "transgredir as formas seculares de antropomorfismo" (2015, p.50). Para Didi-Huberman a figura do acéfalo pode ser lida também como uma derrisão do Homem Vitruviano, de Leonardo da Vinci. A máscara, a derrisão, a desproporção, o esfolamento, são apenas alguns dos procedimentos que Bataille utiliza para questionar o antropomorfismo e, logo, a unidade básica e harmoniosa do "eu".

A própria figura do acéfalo que tanto encantou Bataille, tem sua origem num jogo iconográfico com representações antigas, medievais e renascentistas. Representações que ora apresentam o acéfalo como algo aproximado com os blêmios de que fala o antigo naturalista romano Plínio, o velho; ora como expressões de um sagrado arcaico que substitui a cabeça humana por cabeças de animais, ocorrência comum a variadas culturas, do Egito à Índia. 
Assim, através da fissura que a figura do acéfalo encarna, entra em cena o animal. A animalidade também se converte num expediente para corroer o antropomorfismo racionalista, impondo-lhe o segredo de uma natureza que nunca se abre e que sempre desiste de nos comunicar alguma coisa - como na ironia de Nietzsche ${ }^{5}$.

Todo o esforço de Bataille, afirma Didi-Huberman, constitui uma espécie de refutação da relação entre semelhança e forma, como proposta por São Tomás de Aquino em sua filosofia escolástica; de quebra da identidade entre as coisas, os seres e suas formas. Bataille se interessa pelo informe, e, mais precisamente, pela força com que o informe pode questionar o estatuto de semelhança pressuposto na noção tomista de forma. Isso não significa que a forma não tenha lugar, ou seja um conceito obsoleto para o pensamento e a arte de Bataille; mas ela se converte em traço operativo, dinâmico e, conseqüentemente, sempre aberto ao diferente - um devir da forma:

Transgredir as formas não quer dizer, portanto, desligar-se das formas, nem permanecer estranho ao seu terreno. Reivindicar o informe não quer dizer reivindicar não-formas, mas antes engajar-se em um trabalho das formas equivalente ao que seria um trabalho de parto ou de agonia (...) (DIDIHUBERMAN, 2015, p.29)

Esse trabalho das formas, de que fala Didi-Huberman, pode ser verificado na violência com que Bataillhe ataca o corpo e a figura humana. Violência que se concretiza através de vários expedientes, que vão desde procedimentos com a deformação, a laceração; até uma animalização da figura humana.

Em História do Olho, personagens como Simone e o narrador procedem como se não fossem humanos; estão absolutamente absorvidos por uma pulsão animal. Nada, nenhuma convenção, nenhum senso de moral social os faz retroceder. A cena em que o narrador bolina Simone, sugando-Ihe os seios, quando repentinamente a mãe dela entra no quarto é emblemática: ele continua de maneira absolutamente indiferente o trabalho a que então tanto se dedicava. A mãe resmunga algo e sai. Sem remorso, sem culpa, sem perspectiva e sem futuro - o próprio texto começa de uma maneira tão abrupta quanto a que termina estão livres para atender aos desejos e ao imaginário libertino um do outro. Não têm medo

\footnotetext{
5 O homem pergunta mesmo um dia ao animal: por que não me falas sobre tua felicidade e apenas me observas? $\mathrm{O}$ animal quer também responder e falar, isso se deve ao fato de que sempre esquece o que queria dizer, mas também já esqueceu esta resposta e silencia: de tal modo que o homem se admira disso. (NIETZSCHE, 2003, p.7).
} 
de morrer, as autoridades não os ameaçam. Movem-se dentro da narrativa como se o seu circuito fosse outro, como se habitassem apenas parcialmente o mundo, não se submetendo aos seus limites e interditos.

Por fim, os conceitos de continuidade e descontinuidade na experiência erótica também expressam essa tensão entre o "eu" e o "não-eu". Segundo Bataille em seu famoso ensaio $O$ erotismo (2013), somos existencialmente marcados pela sensação segura de nossa descontinuidade - ou seja: somos descontínuos e aí reside uma das poderosas premissas da preservação da identidade; sou diferente daquilo a que não estou ligado. Nenhuma relação mais estreita se estabelece entre mim e certas formas das quais estou o tempo todo me diferenciando: "Este abismo se situa, por exemplo, entre você que me escuta e eu que the falo. Tentamos nos comunicar, mas nenhuma comunicação entre nós poderá suprimir uma diferença primeira. Se você morrer, não sou eu que morro" (2013, p.37).

A experiência erótica instauraria um princípio de continuidade - de indiferenciação, de indistinção - semelhante à experiência da morte. Daí a profunda conexão que Bataille observa entre a morte e a experiência erótica. No êxtase, um curto-circuito geral dissolve o eu de forma violenta e nesse morrer profundo, sem necessariamente perder a vida, certo saber incandescente reluz através do que extrapola a linguagem e o pensamento, alojandose na soberania sensível da corporeidade. É justamente para aí, para esse ponto insustentável, para essa altitude sem fôlego, que Bataille deseja transferir seu pensamento e sua escrita extasiados.

\section{O texto dilacerado}

Operação análoga ao despedaçamento do olhar, e ao corte da cabeça; é a construção textual de Bataille. Aquilo que se convencionou chamar de fragmentário na literatura moderna adquire em sua obra outro significado. Através de uma perturbação, de uma instabilidade formal, de um processo de dilaceração da noção tradicional de texto, Bataille institui aquilo que podemos chamar de eloqüência do pedaço.

O dilaceramento perpassa toda a escritura de Bataille: ele submete seus textos teóricos e criativos - a uma violência fragmentadora, por vezes, desconcertante. Em outros casos, eles permanecem como esboços truncados, inconclusos, como o trabalho de uma espécie de Da Vinci inconveniente. Cabem no horizonte dessa agressiva fragmentação, desse ritual festivo de desmembramento do Texto, tanto o esboço, o inacabado; como o dissoluto, o derruído, o lacerado. São muitos os exemplos em que o próprio autor faz 
questão de assinalar uma aguda consciência desse processo a que submete seu texto. $\mathrm{Na}$ Experiência interior (2016), a respeito da divisão do livro em partes, afirma o autor: "As únicas partes deste livro escritas por necessidade (...) são a segunda, 'O suplício', e a última. Escrevi as outras com a louvável intenção de compor um livro" (p.28). Seus textos Ihe parecem sempre natimortos, fadados à decomposição antes de nascerem. Essa consciência se aprofunda ao ponto de comprometer a suposta coerência do livro. Após avançar um pouco na composição do texto, subitamente o autor interrompe a argumentação a que se dedica, com o intuito de explicar o conceito de experiência interior; transformando o texto num amontoado de notas que passam a dominar o terceiro capítulo e se prolongam até o final da primeira parte da obra. Eis a maneira abrupta que ele anuncia essa interrupção: "Interrompo novamente o curso da exposição. Não revelarei as razões disso (elas são várias, coincidentes) Limito-me agora a algumas notas que trazem à luz o essencial e sob uma forma que corresponde melhor à minha intenção do que o encadeamento" (p.48). Notas que, muitas vezes, são verdadeiros aforismos.

Tomo exemplos às narrativas de Bataille. Intencionalmente, escolho aquelas que à primeira vista se enquadrariam mais perfeitamente na forma romanesca, como é o caso da já citada História do Olho e o Padre C. No primeiro caso, uma série de elementos vão contribuindo para a noção de trajetória errática: desde a postura existencial das personagens até a maneira abrupta como a narrativa se inicia e termina. Não há aprofundamento da psicologia dos personagens, falta-lhes certa espessura recorrente na tradição do romance europeu desde o realismo e freqüente em toda a literatura da primeira metade do século XX. A história se apresenta como um pedaço de história e as personagens como esboços ou pedaços de personagens. No segundo caso, dá-se algo mais aproximado com o que acontece em $A$ experiência Interior. A partir do quarto capítulo o romance Padre $C$ entre em curto-circuito. A história se dissolve em fragmentos poéticos e farrapos narrativos que, por sua vez, revelam contornos até então insuspeitos da história, numa linguagem alucinada. E é no discurso de um editor, personagem até então ausente da narrativa que se encontra uma chave possível de leitura do caráter despedaçado da narrativa: "Aquelas reflexões interrompidas têm pouco sentido... Ou talvez, é terem sido interrompidas que Ihes dá... um sentido evidentemente fendido. Mas por falta de saber onde levam, até mesmo esse sentido me escapa" (1999, p.138).

\section{CONSIDERAÇÕES FINAIS}

O texto de Bataille parece insistir num tipo residual de consciência. Um tipo de consciência que sobrevive para além do desmembramento do conjunto. Pode ser lida de várias formas, mas as mais importantes talvez sejam aquelas em que a leitura soçobra, dilacera-se ou se dilui o sentido, porque o próprio sentido não passa de um tremeluzir 
rápido e esquivo. Que nada explica, que nada condiciona, resolve ou aclara. Uma luz negra que não dar a ver o não-visto.

Nesse tecido impuro e roto que é a escritura de Bataille, erotismo, dilaceramento e dissolução se encontram e exigem que repensemos nossa noção de texto; mas também - e talvez principalmente - repensemos a noção de sujeito como apresentada pela tradição racionalista da filosofia. Tradição que nos apresenta esse mesmo sujeito como o dono de um olhar que antes observa a ser observado; íntegro em sua unidade e imune ao desejo e às paixões. Bataille se interessa pelo curto-circuito, pelo momento, breve e insustentável, em que o sujeito é implodido pelo gesto de desejar. Gesto esse que é, simultaneamente, também o de criar e o de conhecer. 


\section{Referências Bibliográficas}

BATAILLE, Georges. História do Olho. São Paulo: Companhia das Letras, 2018.

. O Erotismo. Trad. de Fernando Scheibe. São Paulo: Autêntica, 2013.

. A experiência interior. Trad. de Fernando Scheibe São Paulo: Autêntica, 2016.

. O Padre C. Trad. de Renato Aguiar. Rio de Janeiro: Relume-Dumará, 1999.

DIDI-HUBERMAN, Georges. A semelhança informe. Trad. de Cai Meira et Al. Rio de Janeiro: Contraponto, 2015.

NIETZSCHE, Friedrich. Obras Incompletas. São Paulo: Nova Cultural, 1987.

. Segunda Consideração Intempestiva. Trad. de Marco Antonio Casanova. Rio de Janeiro: Relume-Dumará, 2003

SCHOLLHAMMER, Karl Erik. Além do visível: o olhar da literatura. Rio de Janeiro: Sete Letras, 2016.

\footnotetext{
i Possui mestrado em Letras pela Universidade Federal de Pernambuco (2003) e doutorado em Letras pela Universidade Federal de Pernambuco (2008). Atualmente é professor adjunto A-2 do curso de Letras da UFPE (Universidade Federal de Pernambuco) e coordena o Núcleo de Estudos em Literatura, Memória e Imaginário (NULMI). Atua nas áreas de Teoria, Crítica e História Literárias. Tem experiência na área de Literatura comparada e contemporânea, atuando principalmente nos seguintes temas: literatura brasileira contemporânea, poética moderna e contemporânea, literatura e mito; e literatura e memória.
} 